\title{
An Overview of Influencing Factors of Thermal Performance for Open Spaces in the Tropics
}

\author{
Soo Cindel Yung Yung ${ }^{1 *}$, Mahyuddin Norhayati ${ }^{2}$, Ab Ghafar Norafida $^{3}$ \\ 1,2,3 Center for Building, Construction \& Tropical Architecture (BuCTA), Faculty of Built \\ Environment, University of Malaya, 50603 Kuala Lumpur, Malaysia. \\ *cindelsoo@siswa.um.edu.my
}

Received: 31 January 2018 Final Version Received: 16 July 2018

\begin{abstract}
In recent years, urban heat island has become a critical issue especially in the tropics, thereby drawing attention of researchers. Urban heat island poses considerable influence upon the thermal performance of an open space in terms of its social interaction, environmental and therapeutic potentials. To provide benefits towards healthy urban living, proper planning of open spaces is seen to be crucial. In the tropics, the thermal performance of an open space can only be effectively achieved when determinant variables on site and the surroundings are not neglected. This paper provides a comprehensive review of previous studies on the effect of different determinant variables for open spaces with regards to thermal performance in the tropics. Determinant variables such as built forms and configurations, orientation, built envelope and layout, building fabric and surface materials, and natural features like vegetation and water features were reviewed and analysed to identify their influences toward the thermal comfort of open spaces and how the effective passive cooling potential could be enhanced. In conclusion, to achieve the best possible thermal performance for open spaces, determinant variables of greater influence such as built form and configuration, orientation and the built envelope and layout are stressed throughout the design planning.
\end{abstract}

Keywords: Open Spaces, Thermal Comfort, Thermal Performance, Tropics

\section{INTRODUCTION}

With the rapid urban growth, developments in the tropics are progressively growing to the fact that the rationale of developing a thermally optimized open space is no longer a priority (Ahmed, 2003). As studied by Qaid, Lamit, Ossen, and Raja Shahminan (2016), the modification/reformation of a natural ecosystem through modifications caused by changes in land usage will eventually lead to climate imbalance, thus affecting the surrounding temperature and deteriorating quality of the environment. The existence of new construction increases the effect of urban heat island in terms of land cover and urban surface due to the higher tendency of the newly constructed materials to absorb and store heat which then the heat reradiate back to the surroundings (Leal Filho, Echevarria Icaza, Neht, Klavins, \& Morgan, 2018; Qaid et al., 2016; Ramakreshnan et al., 2018; Salleh, Abdul Latif, Wan Mohd, \& Chan, 2013). Urban heat island effect is challenging to mitigate as new buildings and development have supplanted vegetation and trees (Boukhelkhal \& Bourbia, 2016).

In recent years, the thermal performance of open spaces has raised concern amongst researchers due to the overwhelming impact of urban heat island in the tropics (Hu, White, \& Ding, 2016; Qaid et al., 2016). Urban heat island poses considerable influence upon the thermal performance of an open space in term of its social interaction, environmental and therapeutic potentials (Almhafdy, Ibrahim, Ahmad, \& Yahya, 2013). While climate change is unavoidable, it is therefore important to focus on passive design strategies such as careful planning of open space built forms and its layout as it could assist in thermal comfort and wellbeing of the people (Cortesao, Alves, Corvacho, \& Rocha, 2016). As such, it is necessary to be climate-conscious throughout the planning and design of an open space; to allow adequate and proper access of wind and sun. In general, the concepts, theories and area of knowledge from 
planning to designing an open space require proper and careful thought along with the necessary integration of various parties such as urban planners, landscape architects and architects in order to create a well-rounded open space for the end users. (Hussain \& Said, 2014). The climatic design planning of an open space can provide benefits for healthy urban living. In a study by Bulus, Hamid, and Lim (2017a), passive architectural design has become the major component for mitigating temperaturerise in or around buildings. The form of the buildings or walls surrounding the open space plays an important role in determining the thermal performance of an open space. Hereby, the adoption and implementation of climateresponsive designs are crucial to establish a thermally desirable and comfortable environment for occupants of now and then (Altinisik, Klemm, Perretti, \& Bruse, 2014).

This paper provides an overview of different design variables that could influence the thermal performance of an open space in the tropics. Determinant of thermal performance variables such as built forms and configurations, orientation, built envelope and layout, building fabric and surface materials, and natural features like vegetation and water features were reviewed and analysed to identify the factors influencing the thermal performance of open spaces and how the effective passive cooling potential could be enhanced.

\section{OPEN SPACES}

The open space within adjacent buildings have pivotal role in regulating the surrounding microclimate, the cumulative effect of such open spaces could be significant at the urban scale especially in the tropics. Therefore, it is important to design the open space in a built form compatible with the features of the climatic region it is used (Yaşa \& Ok, 2014).

As defined by Shabak, Norouzi, Abdullah, and Khan (2015, p. 40), open spaces refer to "public parks and recreation grounds, grassed areas as open parks, non-shaded urban land/undeveloped natural landscape and neighbouring spaces between buildings which are open for public access". Whereas Hussain and Said (2014) introduce that an open space has a function of supplying fresh air and to act as a medium to facilitate good air circulation in one environment besides enhancing the recreational quality of the surrounding. In this study, an open space is emphasized as an important feature for balancing between the urban fabric and surrounding buildings as well as maintaining the microclimate for the surrounding area in the tropics. Therefore, it is crucial to ensure that the geometry of the open space and its material makeup are taken into consideration during the design stage in order to provide the most optimum level of thermal comfort possible (Meir, 2000).

\section{OUTDOOR THERMAL COMFORT}

According to the American Society of Heating, Refrigerating and Air Conditioning Engineers, ASHRAE (2017) Standard 55, utilizes the environmental factors of air temperature, thermal radiation, humidity, and air speed, as well as the personal factors of activity and clothing. It defines thermal comfort as "specifying the combinations of personal and environmental factors to produce thermal environmental conditions that will be acceptable to a majority of the occupants within a space" whereas, another condition stated by ASHRAE (1992) Standard 55, thermal comfort is defined as "a thermally acceptable environment is when $80 \%$ or more people do not express dissatisfaction". However, the overall thermal comfort and thermal assessment of the surrounding environment do not solely dependent on physical parameters; thermal equilibrium involves three aspects which are physiological (behavioural adjustments), psychological (expectation, past experience, time of exposure, environmental stimulation) and behavioural factors, being used in evaluating thermal comfort (da Silveira Hirashima, de Assis, \& Nikolopoulou, 2016). Besides, another influencing factors of occupants' thermal comfort are the location and topology of the building itself (Frontczak \& Wargocki, 2011).

In general, thermal comfort is classified in relation to the type of environment: indoor, semioutdoor and outdoor. In term of indoor environment, the thermal comfort is highly dependent on mechanism such as heating, ventilation and air conditioning (HVAC) (Enescu, 2017) whereas, for outdoor environment, the thermal comfort of the surrounding can be enhanced using proper building form which; an optimum building form will help in decreasing the cooling load of the outdoor environment (Wan Mohamed Rashdi \& Embi, 2015). There are few assessments to consider while evaluating on the parameters for outdoor thermal comfort, for example, air temperature, wind speed, solar radiation and relative humidity in addition of two personal variables which are activity and clothing 
(Anupriya, 2016). In hot-humid tropics, it is inevitable of having high intensity solar radiation with increasing heat gain and reduced evaporation along the outdoor environment, resulting in overheating and leads to outdoor thermal discomfort.

During the last decade, an increasing number of researchers have studied about outdoor thermal comfort and thermal performance in urban areas of different climates and cultures. Their studies have resulted in the development of a whole new database on thermal comfort indices in varying climates and cultures which is significant in showcasing the contrast and relation between thermal comfort conditions and thermal perception (Ahmed, 2003; Anupriya, 2016; Boukhelkhal \& Bourbia, 2016; Jamei, Rajagopalan, Seyedmahmoudian, \& Jamei, 2016; Taleghani, 2018). As the outdoor environment is much more complex than the indoor environment, the thermal comfort indices developed for the indoors may not be applicable due to spatial and temporal microclimatic variations of meteorological variables such as air temperature and humidity, water surface temperature and wind velocity; which are influencing parameters in evaporation rates (Assouline \& Mahrer, 1995).
Moreover, it is challenging to control the climate in outdoor spaces as compared to indoor spaces, there are numerous aspects to be considered, the subject's physical and socio-cultural adaption as well as the wide variation in the space usage and users' behaviour in the outdoor environment. When it comes to outdoor thermal comfort, it is not only the temperature to consider but also the radiative exchange. Therefore, low sky-viewfactor (SVF) is indeed crucial to maximise shading effect and reduce reflected radiation; to maintain total comfort to all users (Ratti, Raydan, \& Steemers, 2003). However, it is strongly debated that thermal strategies vary from one climatic region to another (Muhaisen, 2006).

\section{FLOWCHART ON RESEARCH METHODOLOGY}

This section will present the research methodology used to review and analyse the previous studies in this paper in comply to answer the problem statement of this research as well as achieving the research aim which is to identify the influencing factors of thermal performance for open spaces in the tropics. Flowchart on research methodology is illustrated in Figure 1.

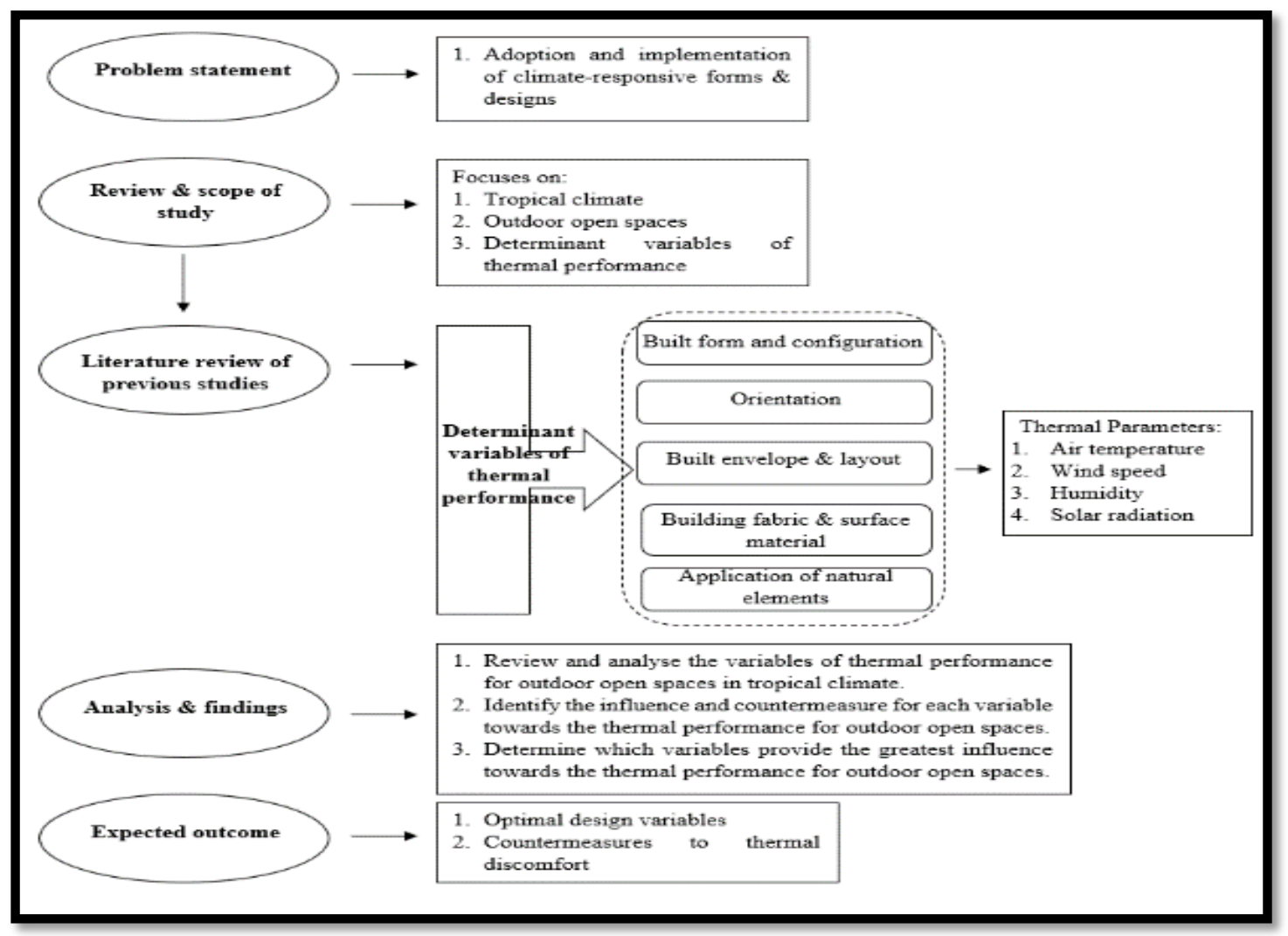

Fig. 1: Flowchart on research methodology used to analyse previous studies. 


\section{THERMAL PERFORMANCE OF OPEN SPACES}

Open spaces come in different forms and functions; be it the space between buildings, open

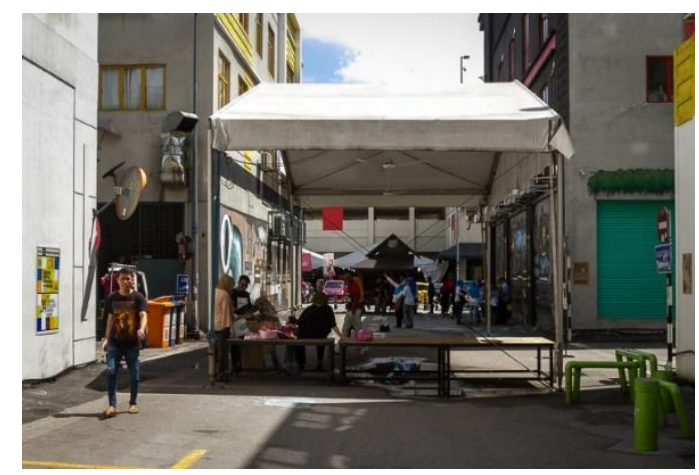

Centralised open space

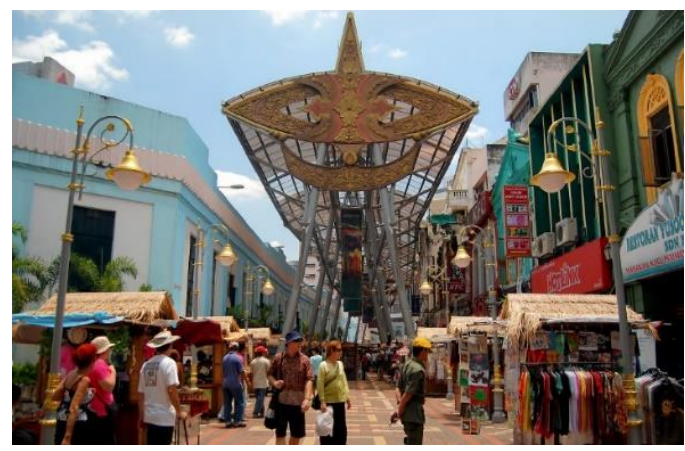

Linear open space

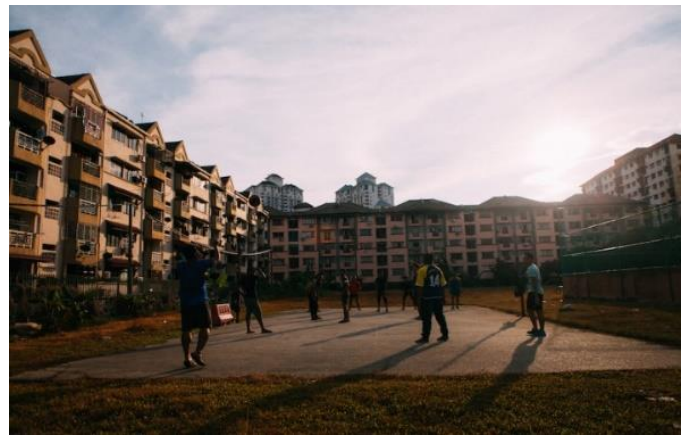

Attached open space

space within adjacent buildings, pedestrian or even streets along buildings whether shaded or unshaded as shown in Figure 2.

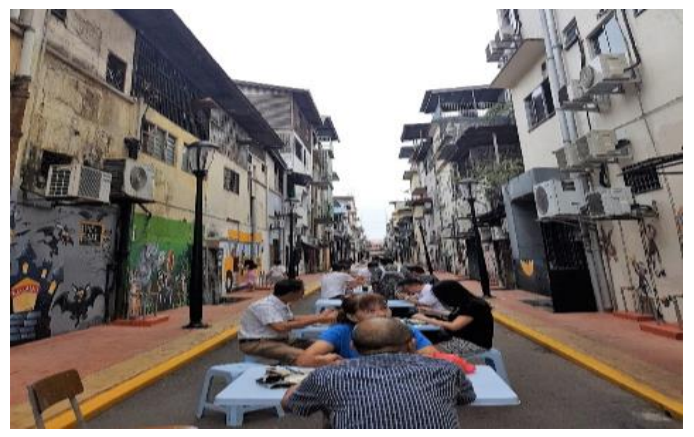

Linear open space

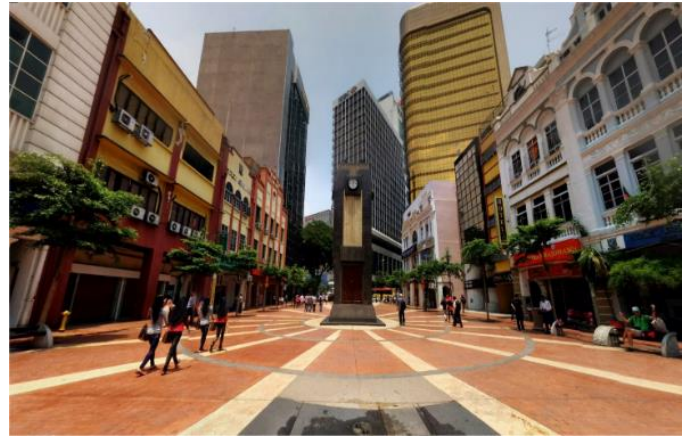

Semi-enclosed open space

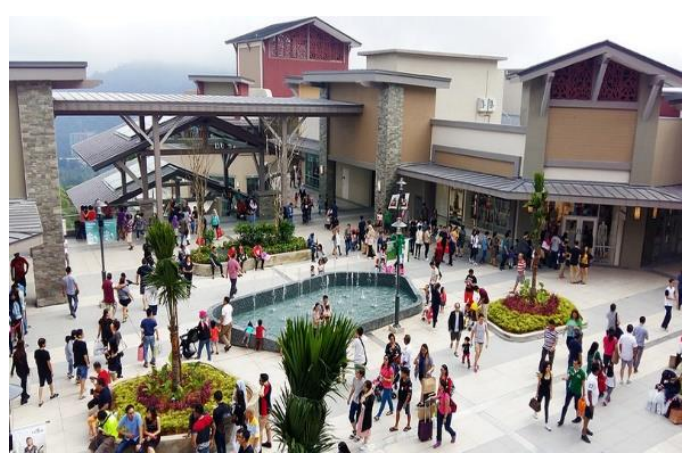

Semi-enclosed open space

Fig. 2: Open spaces of different forms and scales.

The different approaches and criteria of planning and designing an open space are a significant predictor in establishing a sense of attachment among occupants (Shabak et al., 2015). Furthermore, an open space shall be developed to be climate responsive in addition to promoting a natural, comfort environment. Being climate responsive implies that the design forms and parameters are arranged in such a way that the thermal performance of the open space creates an effective and comfortable environment for the occupants (Wong \& Li, 2007). Therefore, it is essential for open spaces to be designed in diverse forms and scales to accommodate and satisfy different purposes. Otherwise, unfavourable conditions are likely to occur which in return handicap the wind circulation and solar accessibility. As a whole, the planning and design of an open space are needed to enable a controllable microclimate for physical thermal 
comfort by using applicable built form and configuration, orientation and also the built envelope and layout of an open space (Lau, Gou, \& Liu, 2014).

\subsection{DETERMINANT OF THERMAL PERFORMANCE VARIABLES OF AN OPEN SPACE}

\subsubsection{BUILT FORM \& CONFIGURATION OF AN OPEN SPACE}

The building form of an open space can be defined based on the surface-to-volume ratio which is dependent on its shape and depth and directly affecting its natural ventilation. In terms of building shape and forms, the surface-tovolume ratio, geometric and building height of open spaces are among the affecting factors in thermal behaviour. The thermal impact on open spaces is dependent on the shades provided within the designated space (Muhaisen, 2006). Chatzidimitriou and Yannas (2015) implied that the built forms alter solar incidence and airflow while properties of fabric materials affect the energy balance of surfaces. In another study, Ratti et al. (2003) examined and conducted analytical studies on the effects of various built shapes and forms on thermal performance in different climatic regions. It is deduced that environmental variables including surface-tovolume ratio, shading, solar accessibility and sky view factor (SVF) are key measures of the overall thermal performance of an open space notably in the tropics. According to Boukhelkhal and Bourbia (2016), it is learned that the main causes of microclimate variation within the open spaces are linked to built form of open spaces, which affects the incoming and outgoing of sun radiation. In the tropics, the higher the open space form, the greater the depth and hence the better shading effect it provides.

Meanwhile, Muhaisen and Gadi had published a number of influential papers on thermal performance of open spaces, which had an enduring influence on the practice and guidelines of open space design. Muhaisen and Gadi (2006a) focused their study mainly on the effect of solar heat gain followed by built form with different proportions. By proportioning the built form and internal envelope in a proper manner, it is possible for an open space to allow adequate solar radiation accessibility while providing sufficient shading; reducing the need for cooling. The geometrical parameters of an open space such as its proportions, size and orientation have significant effect on the shading produced on the form's internal surfaces (Muhaisen \& Gadi, 2006b). As portrayed in Figure 3, centralised (a), semi-enclosed (b) and linear (d) forms are more preferred and effective in the tropics due to a lower sky view factor whereas attached (c) is opted in temperate or colder regions to increase heat gain and solar exposure. Despite having different built forms, an open space may have the same volume as another yet having different façade area. Therefore, the built form of an open space is important to determine the total heat loss through its built envelope and thus affects the thermal performance of the open space (Manioğlu \& Oral, 2015).

In contrast, different shapes and depths of open spaces may result in diverse total surface area of a volume. For instance, two different open spaces may have different surface areas and envelope heat loss despite both open spaces having the same size and utilizing the same fabric materials. Therefore, the optimized building form of an open space is illustrated with the least heat gain and lowest cooling load (Wan Mohamed Rashdi \& Embi, 2015). The lower the surface-to-volume ratio, the more compact the form, the lower the cooling load. To support the above findings, Lau et al. (2014) surmised that it is important to maintain the right height-to-width proportion of an open space. An open space with a height that is equivalent or slightly more than three times its width is believed to be efficient in providing shade whereas the height which is too tall may cause adverse effects on lighting and wind distribution. In addition, an open space that is too shallow may also not be climatic responsive because of its high sky view factor (SVF) thereby allowing it to be exposed directly under the sun. Generally, deep forms of any geometry are able to achieve maximum shading which is recommended in the tropics whereas shallow forms are more preferable in the cooler climates.

As illustrated in Figure 4, Abdulkareem (2015) found that a larger space enables more exposure and would lead to a greater loss of long wave radiant heat. However, this means greater quantities of heat are accumulated due to an increase in surface to volume ratio whereas a smaller and narrower space has limited exposure, resulting in minor loss of long wave radiant heat while collecting minimal quantities of heat during the day. In conclusion, it is better to have a few small open spaces along buildings rather than having one large open space as the shaded area provided in a large open space is lesser as compared to a few small open spaces. Also, Wan Mohamed Rashdi and Embi (2015) established that the size and orientation of an 
open space with regards of the form indeed affects the overall thermal performance of an open space. It is undeniable that an optimum form, orientation and envelope configuration can enhance the overall outdoor thermal performance significantly.

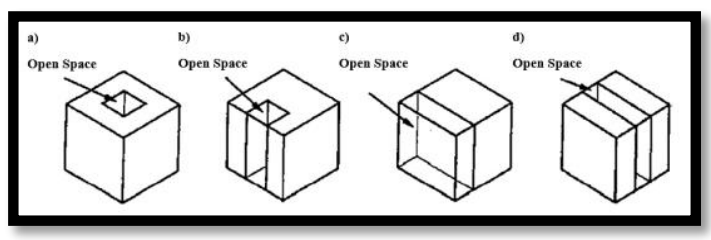

Fig. 3: Four models of different open space form, a) Centralised, b) semi-enclosed, c) attached, d) linear (Source: (Moosavi, Mahyuddin, Ab Ghafar, \& Ismail, 2014)).

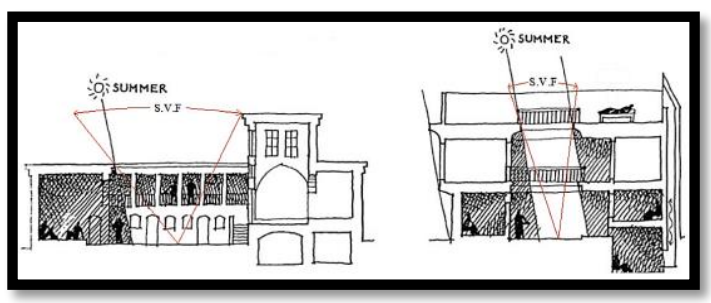

Fig. 4: A comparison of volume-to-surface ratio between single-storey and two-storey open space in terms of their thermal exposure and sky view factor (SVF) (Source: (Abdulkareem, 2015)).

\subsubsection{ORIENTATION OF AN OPEN SPACE}

The orientation of an open space is dependent on the building layout. There are a few variables which are able to positively affect the thermal comfort within an open space, for instance the location of the sun, wind direction, solar gain between building fabric and shading devices from building or landscape furnishing. Meir, Pearlmutter, and Etzion (1995) studied that the orientation of open spaces has a direct effect to natural ventilation and wind speed. Additionally, Xue, Gou, and Lau (2017) deduced that the overall layout and orientation of an open space influence the surrounding microclimate of the open space as well as the neighbouring buildings, affecting solar radiation, shading, wind turbulence, solar access and ventilation performance. In a study on passive design strategies by Akande (2010), it was concluded that a properly oriented open space takes advantage of its surrounding solar radiation and prevailing wind and that the correct form of an open space and its orientation can provide adequate natural cooling and consequently minimize the energy used for cooling. However, Muhaisen (2006) stated that the orientation of an open space relates to the concept of creating shade and minimising heat gain to achieve thermal comfort; where the amount of surface exposure to the sun would gradually affect the thermal performance of the open space. Even a slight adjustment of orientation angle poses a significant effect to the overall thermal performance as shown in Figure 5. As studied by Muhaisen (2006), the optimum orientation angle is when the form has a maximum wall-shaded area in summer and minimum in winter, differs from one climate to another. In the tropics, the maximum wall-shaded area is achieved when the form is elongated along the north-south axis.

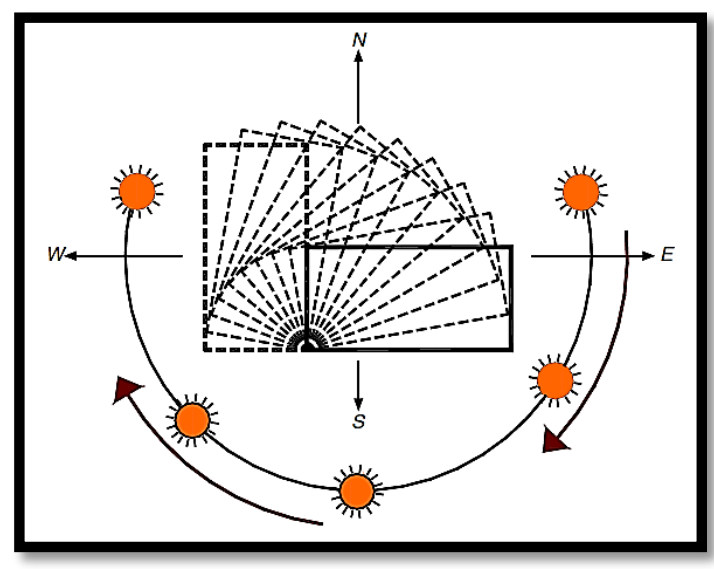

Fig. 5: Changing the orientation of the open space from $0^{\circ}$ to $90^{\circ}$ in $10^{\circ}$ steps (Source: Muhaisen (2006)).

Wong and $\mathrm{Li}$ (2007) performed field measurements and computational energy simulations in a hot-humid climate to investigate the effect of building orientation towards the passive design approach. It was deduced that the best building orientation is achieved when the elongated building facade is perpendicular to the solar radiation. Also, Wan Mohamed Rashdi and Embi (2015) confirmed that in a hot-humid climate, the direction of a longer axis facing east results in a higher cooling load as compared to the other orientations, which is aligned with the fundamental knowledge of orientating the longer axis facing North is the best orientation of a building form. As present in Figure 6, Taleghani, Kleerekoper, Tenpierik, and van den Dobbelsteen (2015) illustrated five models and the position of reference points as well as the sky view factor (SVF) for each form. Sky view factor (SVF) is a dimensionless parameter used to indicate the extent to any point for a given location regardless of its form and the fraction of the overlying hemisphere occupied by the open sky (Oke, 1988). In an open space, a greater sky view factor would typically lead to a higher outdoor air temperature aside from a greater 
amount of solar radiation from the increase of sun exposure. In the tropics, the climate itself becomes a contribution to the preference for a lower sky view factor which is shown in Figure 6(e) (Ramakreshnan et al., 2018). However, the amount of sky view factor requires the consideration towards the wind direction and solar angles to ensure a cooler environment is maintained with sufficient air flow and shading. Therefore, the sky view factor plays a prominent role in influencing the temperature of open spaces especially in the tropics. The orientation of an open space is therefore able to provide the best possible thermal performance depending on its surface exposure to the sun and prevailing wind.

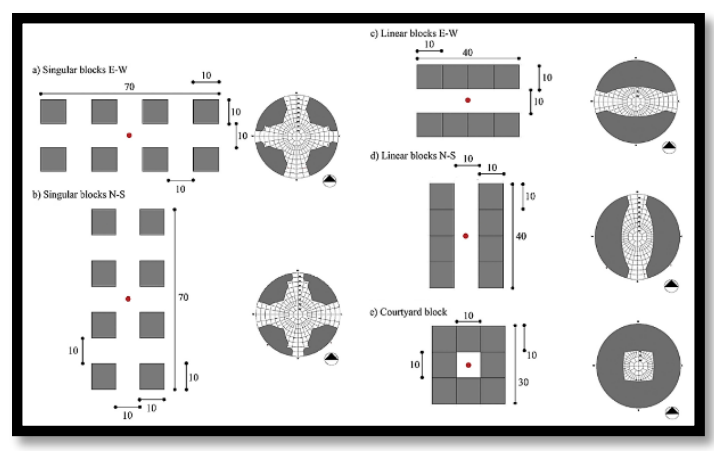

Fig. 6 Left: the five models and the positions of the reference points; Right: the Sky View Factor (SVF) of all the forms (Source: Taleghani et al. (2015)).

\subsubsection{BUILT ENVELOPE AND LAYOUT OF AN OPEN SPACE}

Building envelope is defined as the physical separator between the interior and exterior of a building such as walls, roof, doors, openings and fenestration which widely affects wind movement and heat distribution of the open spaces within a building (Straube, 2006). In the tropics, the ultimate objective of a good envelope design is the reduction of direct heat gain via solar radiation through all forms of openings from the surrounding area without compromising the natural ventilation from prevailing wind, and thus prevent overheating and microclimate variation (Muhaisen, 2006; Rajapaksha, Nagai, \& Okumiya, 2003). Therefore, envelope design is varied and dependent on climate conditions. Wall enclosures also play a significant role in thermal performance of an open space through natural ventilation (Bulus et al., 2017a). Wind speed and wind direction can be easily diverged by openings or by altering the wall to window ratio. Sadafi, Salleh, Lim, and Jaafar (2011) found that the thermal performance of an open spaces is highly dependent on envelope openings and further suggested the application of sufficient openings with shading devices. However, there is a minor drawback of allowing outdoor air into the buildings; it may result in a dustier environment due to pollutants from the atmosphere. Consequently, it is crucial to provide sufficient shading to the open space while maintaining the wind breeze by providing the open space with green coverage (Lau et al., 2014).

In addition, Moosavi et al. (2014) discovered that the introduction of an inlet opening at a low level of the windward side could help to increase the ventilation rate and promote air flow; thereby providing fresh cool air into the surroundings. Therefore, not only does the focus have to be on envelope design, but various other effects and design changes may constitute to better air flow and natural ventilation overall, and also contributing to better thermal performance. It is crucial to allow cool air to circulate within the environment as cooled air has a very high density; it sinks down to the surface and undergoes heat exchange. This results in conventional heat transfer playing a fundamental role in creating a cooler environment overall.

\subsubsection{BUILDING FABRIC AND SURFACE MATERIAL OF AN OPEN SPACE}

Where building fabric is concerned, the fabric materials used within an open space can also be accorded some importance. Fabric and surface materials used should be selected in consideration of being able to balance between the reflected and absorbed solar radiation to optimize the thermal comfort during daytime and to mitigate the heat island during the nighttime (Qaid et al., 2016). The surface of such spaces are often made of high heat capacity materials, for instance, floor tiles, surrounding walls and landscape furnishings tend to store heat and contribute as a heat source; the accumulated heat is then dissipated within the open space itself (Abdulkareem, 2015). The thermal mass of building fabric and surface material of an open space would also subsequently interfere with the rate of heat exchange within an open space (Rajapaksha et al., 2003). In another study by Muhaisen and Gadi (2006a), they determined that the solar radiation received by the open space's surface is deem to be the predominant factor affecting the overall thermal performance of an open space, also depending on the location and its climate conditions as well as the configurations of the built form. The solar radiation which absorbed into the surface of 
open spaces increase the surface temperatures and thus the temperature of the adjacent air layers which eventually leads to drastic thermal conditions. To remedy this problem, fabric and surface materials with high reflectivity "high albedo" will help to minimize the absorption of solar radiation and therefore reduce its restitution in long wavelength during the night.

In the tropics, cool materials with lower thermal conductivity, thermal diffusivity and absorptivity such as light concrete and light asphalt are opted as an alternative to permit lesser heat absorption and lower surface temperatures as compared to other conventional fabric materials (Altinisik et al., 2014; Latha, Darshana, \& Venugopal, 2015). Therefore, the use of cool materials or improvisation of conventional materials by modifying the composition should be introduced for new construction or during building rehabilitation as a strategy to address thermal discomfort and also to reduce the negative effects of the urban heat island (Latha et al., 2015).

\subsubsection{APPLICATION OF NATURAL ELEMENTS FOR NATURAL COOLING IN OPEN SPACE}

In the tropics, the application of natural elements is key to formulating mitigation measures as a replacement to hard surfaces and treatment of anthropogenic emissions (Duarte, Shinzato, Gusson, \& Alves, 2014). Thereby, application of design elements such as vegetation and water features take advantage of existing structure and thus contribute to the microclimate of the open spaces (Cortesao et al., 2016). As studied by Anupriya (2016), the microclimatic condition of the urban atmosphere is very much affected by development and congested composition of the urban landscape, which significantly causes thermal discomfort to the surrounding occupants. However, the thermal performance within open spaces can be improved by equipping with system for evaporative cooling and effect of vegetation.

The existence of water bodies such as artificial ponds and water fountains create a cooling effect in the open space and helps in fostering an evaporative cooling effect and reduces air temperature, thus leading to better thermal comfort for the occupants (Abdulkareem, 2015). However, the size and scale of the type of water bodies matter to significantly provide the cooling effect. For instance, a small pond or small fountain will not have significant effect for a wide scale open space. During evaporation, the sensible heat evaporates the water and cools the air in the open space, resulting in a cooler environment. As the geometry, location and surrounding landscape are determinant factors affecting the evaporative cooling potential of the water bodies, thus open spaces intergrating with water bodies are necessary to be adequately proportioned for evaporation and to avoid excessive humidity to maintain the most suitable humidity level for the occupants of the open space (Thani, Nik Mohamad, \& Idilfitri, 2012). Qaid et al. (2016) state that it is more important to direct the open space towards a body of water rather than directing it against the solar radiation to take advantage of the breeze. Therefore, the open space layout and direction are to be designed in such a way that it is able to address the negative local climate, which either in the direction of the prevailing wind or the intersection of the solar radiation.

Meanwhile, the measure of vegetation along and within the open spaces can contribute in natural cooling to the environment as well as influencing factors to the surrounding microclimate in terms of shading and ventilation (Anupriya, 2016; Duarte et al., 2014; Hsieh, Jan, \& Zhang, 2016). Vegetation is often included in design planning due to its thermal benefits and minimisation of microclimatic variation. The effect of vegetation is considered as a modifying factor of the local climate and it is always the design element well preferred by building designers in order to enhance the surrounding urban microclimate and outdoor thermal comfort of an open space by providing shading and evapotranspiration (Anupriya, 2016; Duarte et al., 2014). Apart from mitigating increased temperature, vegetation also has the potential to reduce the outdoor cooling load demand which can eventually enhance indoor thermal comfort. In short, a difference in temperature is notable depending on the amount of green areas, vegetation types, environment conditions, location, urban densities and surrounding building height (Perini \& Magliocco, 2014).

However, poor tree planting planning would result in a decrease of wind speed which significantly affects thermal comfort. Even though trees are able to mitigate urban heat through evapotranspiration and shading, the density and positioning of the trees have implications towards the wind speed and thermal comfort of the open space (Altinisik et al., 2014). The density of the vegetation will influence the wind velocity and relative humidity, which overall may disrupt human thermal comfort rather than enhancing it (Thani et al., 2012). For 
example, open spaces with high traffic flow are recommended with low dense of canopy to ensure the polluted air emitted from vehicles are able to free flow into the environment rather than stagnant under the canopy. Hence, careful planning of urban greenery within the open space requires detailed analyse such as plant materials and planting configurations. In addition, Gómez-Muñoz, Porta-Gándara, and Fernández (2010) studied the relation between shade and height/width of different tree species and deduced that the width of a tree is more important than the height as it is able to provide a greater shade surface. Therefore, it is important to understand the setback of vegetation on thermal comfort, as it is essential to establish the guidelines and recommendations on the proportion, orientation, types of vegetation and its density, for which improper implementation will lead to either a cooling or warming effect (Jamei et al., 2016).

\subsection{ANALYSIS AND FINDINGS}

In a study by Berkovic, Yezioro, and Bitan (2012) on outdoor thermal comfort, shading is the best means for comfort in the tropics, nevertheless it also depends on the built form and configuration, orientation and the built envelope and layout of the open spaces to determine the prevailing wind and solar access. Among other factors influencing the thermal performance in open spaces are the heat transfer characteristics of the surrounding walls, the greening rate and water coverage rate. As proven by Chang et al. (2016), the wind presence and its frequency increases the occupants' tolerance towards outdoor open spaces. On the other hand, the increase of air temperature and its relative humidity influences a direct adverse effect. As such, it is imperative to study the relationship between thermal performance and thermal parameters which consist of air temperature, humidity, wind speed and solar radiation (Chang et al., 2016).

The determinant variables of thermal performance for open spaces include, built form and configuration, and orientation as well as the built envelope and layout. In addition, building fabric and surface materials along with natural elements like vegetation and water features do important roles in improving the thermal performance for open spaces. However, the more influential variables are determined to be the built form and configuration, orientation and the built envelope and layout as it would strongly affect the thermal parameters such as air temperature, humidity, wind speed and solar radiation. Changes in the aforementioned variables will eventually influence the outdoor thermal performance and consequently the indoor thermal performance, thereby compromising thermal comfort. Therefore, the built form and configuration, orientation and the built envelope and layout are identified to be the primary variables as they are intra-related to the thermal performance of an open space whereas, building fabric and surface materials as well as natural elements like vegetation and water features all act as secondary variables as they are inter-related to the thermal performance of an open space. The determinant variables of thermal performance for open spaces are illustrated in the framework as in Figure 7.

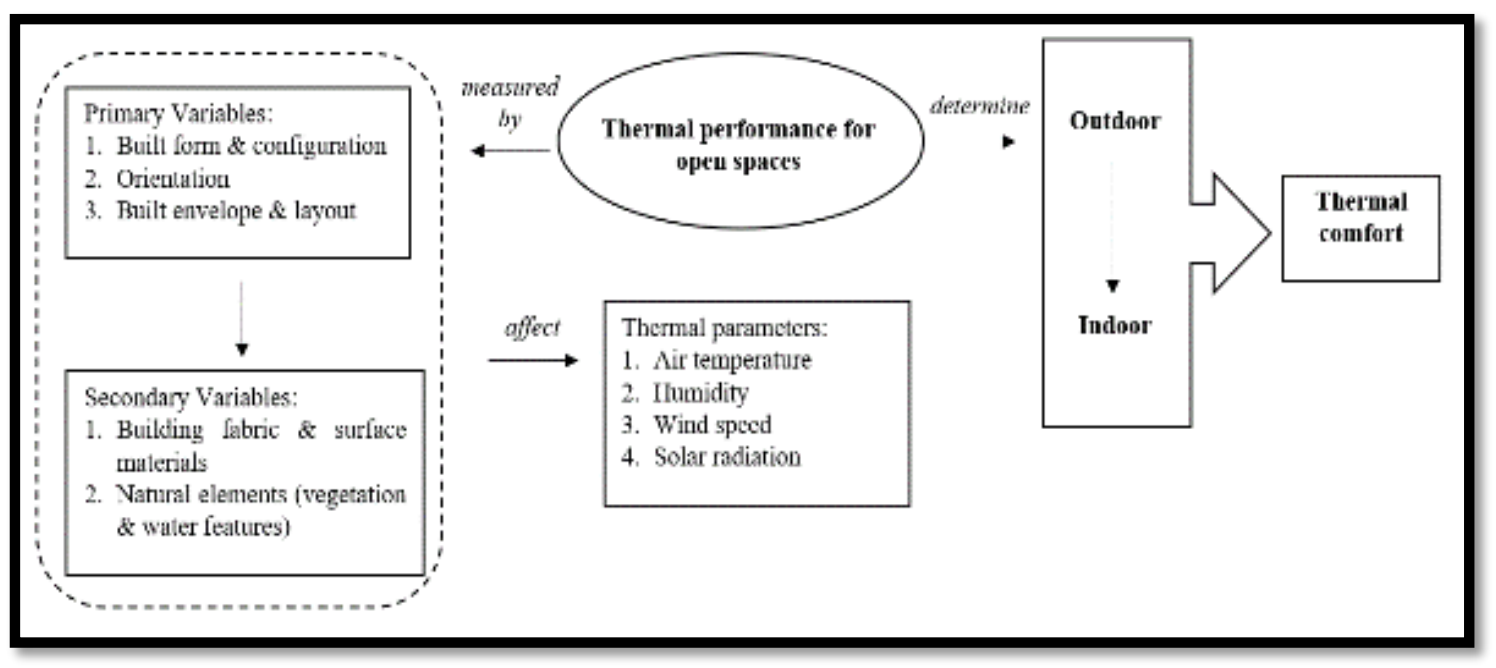

Fig. 7: A framework of determinant variables of thermal performance for open spaces 
In the tropics, it is especially important that an open space is effectively shaded to maintain its optimum thermal performance and not adversely affected by microclimate factors, particularly wind and solar radiation (Soflaei, Shokouhian, \& Mofidi Shemirani, 2016). However, numerous studies have proven that the design variables and the affecting factors of thermal performance vary for differing climate conditions. For instance, open space is commonly shaded in the tropics while in temperate or colder regions, it is unshaded to receive solar radiation. As in this study, the determinant variables of thermal performance for open spaces in the tropics are reviewed and analysed. The findings of the determinant variables of thermal performance for open spaces in the tropics are summarized as seen in Table 1.

Table 1: Findings of the Design Parameters of Thermal Performance for Open Spaces in the Tropics

\begin{tabular}{|c|c|c|}
\hline Design Parameters & $\begin{array}{l}\text { Findings } \\
\end{array}$ & Reference \\
\hline $\begin{array}{l}\text { Building form \& } \\
\text { configuration }\end{array}$ & $\begin{array}{l}\text { 1. The higher the open space form, the greater } \\
\text { the depth and hence the better shading effect } \\
\text { it provides. } \\
\text { 2. The lower the surface-to-volume ratio, the } \\
\text { more compact the form, the lower the cooling } \\
\text { load. } \\
\text { 3. Optimized building form is with least heat } \\
\text { gain and lowest cooling load. } \\
\text { 4. The greater sky view factor would lead to } \\
\text { greater outdoor air temperature, therefore } \\
\text { right amount of solar exposure is preferred } \\
\text { especially in the tropics. }\end{array}$ & $\begin{array}{l}\text { (Abdulkareem, 2015; } \\
\text { Berkovic et al., 2012; } \\
\text { Boukhelkhal \& Bourbia, } \\
\text { 2016; Chang et al., 2016; } \\
\text { Chatzidimitriou \& } \\
\text { Yannas, 2015; Lau et al., } \\
\text { 2014; Manioğlu \& Oral, } \\
\text { 2015; Muhaisen, 2006; } \\
\text { Muhaisen \& Gadi, 2006a, } \\
\text { 2006b; Ratti et al., 2003; } \\
\text { Wan Mohamed Rashdi \& } \\
\text { Embi, 2015) }\end{array}$ \\
\hline Orientation & $\begin{array}{l}\text { 1. The orientation of an open space determines } \\
\text { the amount of shading. } \\
\text { 2. The best orientation of a rectangular open } \\
\text { space is North-South; having the longer } \\
\text { facades facing East and West }\end{array}$ & $\begin{array}{l}\text { (Akande, 2010; Isaac A } \\
\text { Meir et al., 1995; } \\
\text { Muhaisen, 2006; } \\
\text { Ramakreshnan et al., } \\
\text { 2018; Taleghani et al., } \\
\text { 2015; Wan Mohamed } \\
\text { Rashdi \& Embi, 2015; } \\
\text { Wong \& Li, 2007; Xue et } \\
\text { al., 2017) }\end{array}$ \\
\hline $\begin{array}{l}\text { Building envelope } \\
\& \text { layout }\end{array}$ & $\begin{array}{l}\text { 1. A good envelope design reduces the direct } \\
\text { heat gain via solar radiation through all forms } \\
\text { of openings from the surrounding area } \\
\text { without compromising the natural ventilation } \\
\text { from prevailing wind. } \\
\text { 2. Wind speed and wind direction can be easily } \\
\text { diverged by openings or by altering the wall } \\
\text { to window ratio. }\end{array}$ & 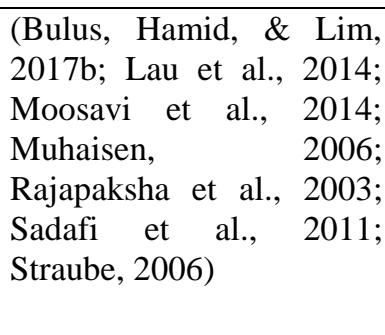 \\
\hline $\begin{array}{l}\text { Building fabric \& } \\
\text { surface material }\end{array}$ & $\begin{array}{l}\text { 1. High heat capacity materials tend to store } \\
\text { heat and contribute as a heat source within } \\
\text { the open space itself. Therefore, cool } \\
\text { materials with lower thermal conductivity, } \\
\text { thermal diffusivity and absorptivity or } \\
\text { improvisation of conventional materials are } \\
\text { opted as an alternative. } \\
\text { 2. Surface materials with high reflectivity "high } \\
\text { albedo" will help to minimize the absorption } \\
\text { of solar radiation and therefore reduce its } \\
\text { restitution in long wavelength during the } \\
\text { night. }\end{array}$ & $\begin{array}{l}\text { (Abdulkareem, } \\
\text { Altinisik et al., 2015; } \\
\text { Latha et al., 2014; } \\
\text { Muhaisen \& Gadi, } 2006 \text {; } \\
\text { Qaid et al., 2016; } \\
\text { Rajapaksha et al., 2003) }\end{array}$ \\
\hline
\end{tabular}




\begin{tabular}{|l|l|l|l|}
\hline $\begin{array}{l}\text { Application of } \\
\text { natural elements }\end{array}$ & $\begin{array}{l}\text {. } \begin{array}{l}\text { The existence of water bodies helps in } \\
\text { fostering an evaporative cooling effect and } \\
\text { reduces air temperature. }\end{array} \\
\begin{array}{l}\text { The presence of vegetation contributes to } \\
\text { natural cooling by providing shade and } \\
\text { ventilation. }\end{array}\end{array}$ & $\begin{array}{l}\text { (Abdulkareem, 2015; } \\
\text { Altinisik et al., 2014; } \\
\text { Anupriya, 2016; Cortesao } \\
\text { et al., 2016; Duarte et al., } \\
\text { 2014; Gómez-Muñoz et } \\
\text { al., 2010; Hsieh et al., } \\
\text { 2016; Jamei et al., 2016; } \\
\text { Perini \& Magliocco, 2014; } \\
\text { Qaid et al., 2016; Thani et } \\
\text { al., 2012) }\end{array}$ \\
\hline
\end{tabular}

These design requirements indicated for the tropics may not be applicable for cold climates as it may create adverse effects. The design requirements for optimum thermal performance of open spaces are manifested not only in the need to reduce heat gains/losses but also to counterbalance the effects of climate changes. Therefore, it is crucial that a study is conducted for design requirements of an open space prior to actual implementation in order to provide adequate countermeasures to urban heat island. Consequently, it is possible to achieve the most optimum thermal performance in an open space by having the determinant variables addressed and applied accordingly to the climate.

\section{CONCLUSIONS}

This paper presents a comprehensive overview study of previous research on thermal performance of open spaces and its determinant variables in the tropics. Determinant variables such as the built form and configuration, orientation, the built envelope and layout, building fabric and surface materials, and natural features were reviewed and analysed to identify their influence towards the thermal performance of open space. The reviews demostrate how the factors of thermal performance can be employed and improved to enhance the thermal performance for open spaces in the tropics. In addition, the reviews also highlighted on the potential and limitation of the options available.

\section{ACKNOWLEDGMENTS}

This study has been made possible with the guidance and support from senior lecturer of University of Malaya, Dr. Sr. Norhayati Binti Mahyuddin and Dr. Norafida Binti Ab Ghafar. This study is supported in part by University of Malaya Research grant (UMRG) under sustainable science research cluster (RP028D-18SUS: UM Cooling Campus: Enhancing Outdoor Thermal).

\section{REFERENCES}

Abdulkareem, H. A. (2015). Thermal Comfort through the Microclimates of the Courtyard. A Critical Review of the Middle-eastern Courtyard House as a Climatic Response. Paper presented at the Urban Planning and Architecture Design for Sustainable Development, UPADSD.

Ahmed, K. S. (2003). Comfort in Urban Spaces: Defining the Boundaries of Outdoor Thermal Comfort for the Tropical Urban Environments. Energy and Buildings(35), 103-110.

Akande, O. K. (2010). Passive Design Strategies for Residential Buildings in a Hot Dry Climate in Nigeria Transactions on Ecology and the Environment (Vol. 128, pp. 61-71): WIT Press.

Almhafdy, A., Ibrahim, N., Ahmad, S., \& Yahya, J. (2013). Analysis of the Courtyard Functions and its Design Variants in the Malaysian Hospitals. Paper presented at the Asia Pacific International Conference on Environment-Behaviour Studies, AicEBs2013London, University of Westminster, London, UK.

Altinisik, L., Klemm, W., Perretti, G., \& Bruse, M. (2014). Integration of Microclimate-Responsive Design in the Planning of Urban Outdoor Spaces - a Case Study in Athens, Greece. Paper presented at the Third International Conference on Countermeasures to Urban Heat Island, Venice, Italy.

Anupriya, S. (2016). Exploratory Study on the Relation between Urban Landscapes and Urban Corridors for Outdoor Thermal Comfort. Paper presented at the International Conference on Emerging Trends in Engineering, Science and Technology (ICETEST).

ASHRAE. (1992). Standard 55-1992:“Thermal Environmental Conditions for Human Occupancy"; ASHRAE Atlanta USA. 
ASHRAE. (2010). Standard 55-2010:"Thermal Environmental Conditions for Human Occupancy"; ASHRAE Atlanta USA.

ASHRAE. (2017). Standard 55-2017:"Thermal Environmental Conditions for Human Occupancy"; ASHRAE Atlanta USA.

Assouline, S., \& Mahrer, Y. (1995). Spatial and Temporal Variability in Microclimate and Evaporation over Lake Kinneret Experiment Evaluation. Journal of Applied Meteorology, 35, 1076-1084.

Berkovic, S., Yezioro, A., \& Bitan, A. (2012). Study of Thermal Comfort in Courtyards in a Hot Arid Climate. Solar Energy, $\quad 86(5), \quad$ 1173-1186. doi:10.1016/j.solener.2012.01.010

Boukhelkhal, I., \& Bourbia, P. F. (2016). Thermal Comfort Conditions in Outdoor Urban Spaces: Hot Dry Climate -Ghardaia- Algeria. Paper presented at the 4th International Conference on Countermeasures to Urban Heat Island (UHI)

Bulus, M., Hamid, M., \& Lim, Y. W. (2017a). Courtyard as a Passive Cooling Strategy in Buildings. International Journal of Built Environment and Sustainability, 4(1), 48-55. doi:10.11113/ijbes.v4.n1.159

Bulus, M., Hamid, M., \& Lim, Y. W. (2017b). Courtyard as a Passive Cooling Strategy in Buildings. International Journal of Built Environment and Sustainability, $4(1)$. doi:10.11113/ijbes.v4.n1.159

Chang, H., Xiang, C., Duan, C., Wan, Z., Liu, Y., Zheng, Y., ... Shu, S. (2016). Study on the Thermal Performance and Wind Environment in a Residential Community. International Journal of Hydrogen Energy, 41(35), 1586815878. doi:10.1016/j.ijhydene.2016.03.039

Chatzidimitriou, A., \& Yannas, S. (2015). Microclimate Development in Open Urban Spaces: The Influence of Form and Materials. Energy and Buildings, 108 , 156-174. doi:10.1016/j.enbuild.2015.08.048

Cortesao, J., Alves, F. B., Corvacho, H., \& Rocha, C. (2016). Retrofitting public spaces for thermal comfort and sustainability. Indoor and Built Environment, 25(7), 1085-1095. doi:10.1177/1420326x16659326

da Silveira Hirashima, S. Q., de Assis, E. S., \& Nikolopoulou, M. (2016). Daytime Thermal Comfort in Urban Spaces: A Field Study in Brazil. Building and
Environment, $\quad 107, \quad 245-253$. doi:10.1016/j.buildenv.2016.08.006

Duarte, D., Shinzato, P., Gusson, C., \& Alves, C. (2014). The Impact of Vegetation on Urban Microclimate to Counterbalance Built Density in a Subtropical Changing Climate. Paper presented at the 30th INTERNATIONAL PLEA CONFERENCE, CEPT University, Ahmedabad.

Enescu, D. (2017). A Review of Thermal Comfort Models and Indicators for Indoor Environments. Renewable and Sustainable Energy Reviews, 79, 13531379. doi:10.1016/j.rser.2017.05.175

Frontczak, M., \& Wargocki, P. (2011). Literature Survey on How Different Factors Influence Human Comfort in Indoor Environments. Building and Environment, 46(4), 922-937. doi:http://dx.doi.org/10.1016/j.builden v.2010.10.021

Gómez-Muñoz, V. M., Porta-Gándara, M. A., \& Fernández, J. L. (2010). Effect of Tree Shades in Urban Planning in Hot-arid Climatic Regions. Landscape and Urban Planning, 94(3-4), 149-157. doi:10.1016/j.landurbplan.2009.09.002

Hsieh, C., Jan, F., \& Zhang, L. (2016). A Simplified Assessment of How Tree Allocation, Wind Environment, and Shading Affect Human Comfort. Urban Forestry \& Urban Greening, 18, 126-137. doi:10.1016/j.ufug.2016.05.006

Hu, Y., White, M., \& Ding, W. (2016). An Urban Form Experiment on Urban Heat Island Effect in High Density Area. Paper presented at the 4th International Conference on Countermeasures to Urban Heat Island (UHI)

Hussain, Y. S., \& Said, I. (2014). Knowledge Integration between Planning and Landscape Architecture in Contributing to a Better Open Space. Paper presented at the Asian Conference on Environment-Behaviour Studies, AcE-Bs2014Seoul, ChungAng University, Seoul, S. Korea.

Jamei, E., Rajagopalan, P., Seyedmahmoudian, M., \& Jamei, Y. (2016). Review on the Impact of Urban Geometry and Pedestrian Level Greening on Outdoor Thermal Comfort. Renewable and Sustainable Energy Reviews, 54, 10021017. doi:10.1016/j.rser.2015.10.104

Latha, P. K., Darshana, Y., \& Venugopal, V. (2015). Role of Building Material in Thermal Comfort in Tropical 
Climates - A Review. Journal of Building Engineering, 3, 104-113. doi:10.1016/j.jobe.2015.06.003

Lau, S. S. Y., Gou, Z., \& Liu, Y. (2014). Healthy Campus by Open Space Design: Approaches and Guidelines. Frontiers of Architectural Research, 3(4), 452467. doi:10.1016/j.foar.2014.06.006

Leal Filho, W., Echevarria Icaza, L., Neht, A., Klavins, M., \& Morgan, E. A. (2018). Coping with the Impacts of Urban Heat Islands. A Literature Based Study on Understanding Urban Heat Vulnerability and the Need for Resilience in Cities in a Global Climate Change Context. Journal of Cleaner Production, 171, 1140-1149. doi:10.1016/j.jclepro.2017.10.086

Manioğlu, G., \& Oral, G. K. (2015). Effect of Courtyard Shape Factor on Heating and Cooling Energy Loads in Hot-dry Climatic Zone. Paper presented at the 6th International Building Physics Conference, IBPC.

Meir, I. A. (2000). Courtyard Microclimate: A Hot Arid Region Case Study. Paper presented at the Architecture-CityEnvironment. Proc. 17th PLEA Int. Conference.

Meir, I. A., Pearlmutter, D., \& Etzion, Y. (1995). On the microclimatic behavior of two semi-enclosed attached courtyards in a hot dry region. Building and Environment, 30(4), 563-572. doi:10.1016/0360-1323(95)00018-2

Moosavi, L., Mahyuddin, N., Ab Ghafar, N., \& Ismail, M. A. (2014). Thermal Performance of Atria: An Overview of Natural Ventilation Effective Designs. Renewable and Sustainable Energy Reviews, 34, 654-670. doi:10.1016/j.rser.2014.02.035

Muhaisen, A. S. (2006). Shading Simulation of the Courtyard Form in Different Climatic Regions. Building and Environment, 41(12), 1731-1741. doi:10.1016/j.buildenv.2005.07.016

Muhaisen, A. S., \& Gadi, M. (2006a). Effect of Courtyard Proportions on Solar Heat Gain and Energy Requirement in the Temperate Climate of Rome. Building and Environment, 41(3), 245-253. doi:10.1016/j.buildenv.2005.01.031

Muhaisen, A. S., \& Gadi, M. (2006b). Shading Performance of Polygonal Courtyard Forms. Building and Environment, 41(8), 1050-1059. doi:10.1016/j.buildenv.2005.04.027

Oke, T. R. (1988). Street Design and Urban Canopy Layer Climate. Energy and
Buildings, $\quad 11(1), \quad 103-113$. doi:https://doi.org/10.1016/03787788(88)90026-6

Perini, K., \& Magliocco, A. (2014). Effects of Vegetation, Urban Density, Building Height, and Atmospheric Conditions on Local Temperatures and Thermal Comfort. Urban Forestry \& Urban Greening, 13(3), 495-506. doi:10.1016/j.ufug.2014.03.003

Qaid, A., Lamit, H., Ossen, D. R., \& Raja Shahminan, R. N. (2016). Urban Heat Island and Thermal Comfort Conditions at Micro-climate Scale in a Tropical Planned City. Energy and Buildings, 133, 577-595. doi:10.1016/j.enbuild.2016.10.006

Rajapaksha, I., Nagai, H., \& Okumiya, M. (2003). A Ventilated Courtyard as a Passive Cooling Strategy in the Warm Humid Tropics. Renewable Energy, 28(11), 1755-1778. doi:10.1016/s09601481(03)00012-0

Ramakreshnan, L., Aghamohammadi, N., Fong, C. S., Ghaffarianhoseini, A., Ghaffarianhoseini, A., Wong, L. P., .. . Sulaiman, N. M. (2018). A Critical Review of Urban Heat Island Phenomenon in the Context of Greater Kuala Lumpur, Malaysia. Sustainable Cities and Society, 39, 99-113. doi:10.1016/j.scs.2018.02.005

Ratti, C., Raydan, D., \& Steemers, K. (2003). Building Form and Environmental Performance Archetypes, Analysis and an Arid Climate. Energy and Buildings, 35, 49-59.

Sadafi, N., Salleh, E., Lim, C. H., \& Jaafar, Z. (2011). Evaluating Thermal Effects of Internal Courtyard in a Tropical Terrace House by Computational Simulation. Energy and Buildings, 43(4), 887-893. doi:10.1016/j.enbuild.2010.12.009

Salleh, S. A., Abdul Latif, Z., Wan Mohd, W. M. N., \& Chan, A. (2013). Factors Contributing to the Formation of an Urban Heat Island in Putrajaya, Malaysia. Paper presented at the Asia Pacific International Conference on Environment-Behaviour Studies, AicEBs2013London, University of Westminster, London, UK.

Shabak, M., Norouzi, N., Abdullah, A. M., \& Khan, T. H. (2015). Children's Sense of Attachment to the Residential Common Open Space. Paper presented at the Asian Conference on EnvironmentBehaviour Studies, AcE-Bs2015, Tehran, Iran. 
Soflaei, F., Shokouhian, M., \& Mofidi Shemirani, S. M. (2016). Traditional Iranian courtyards as microclimate modifiers by considering orientation, dimensions, and proportions. Frontiers of Architectural Research, 5(2), 225 238. doi:10.1016/j.foar.2016.02.002

Straube, J. (2006). The Building Enclosure. Building Science Digest, 018, 1-14. Retrieved from

Taleghani, M. (2018). Outdoor Thermal Comfort by Different Heat Mitigation Strategies- A Review. Renewable and Sustainable Energy Reviews, 81, 20112018. doi:10.1016/j.rser.2017.06.010

Taleghani, M., Kleerekoper, L., Tenpierik, M., \& van den Dobbelsteen, A. (2015). Outdoor Thermal Comfort within Five Different Urban Forms in the Netherlands. Building and Environment, $\quad 83, \quad 65-78$. doi:10.1016/j.buildenv.2014.03.014

Thani, S. K., Nik Mohamad, N. H., \& Idilfitri, S. (2012). Modification of Urban Temperature in Hot-Humid Climate Through Landscape Design Approach: A Review. Paper presented at the ASIA Pacific International Conference on Environment-Behaviour Studies, AicEBs2012 Cairo, Mercure Le Sphinx Cairo Hotel, Giza, Egypt.

Wan Mohamed Rashdi, W. S. S., \& Embi, M. R. (2015). Analysing Optimum Building form in Relation to Lower Cooling Load. Paper presented at the Indonesia, AMER International Conference on Quality of Life, AicQoL2015Jakarta, The Akmani Hotel, Jakarta, Indonesia.

Wong, N. H., \& Li, S. (2007). A Study of the Effectiveness of Passive Climate Control in Naturally Ventilated Residential Buildings in Singapore. Building and Environment, 42(3), 1395-1405. doi:10.1016/j.buildenv.2005.11.032

Xue, F., Gou, Z., \& Lau, S. S. Y. (2017). Green Open Space in High-Dense Asian Cities: Site Configurations, Microclimates and Users' Perceptions. Sustainable Cities and Society, 34, 114125. doi:10.1016/j.scs.2017.06.014

Yaşa, E., \& Ok, V. (2014). Evaluation of the Effects of Courtyard Building Shapes on Solar Heat Gains and Energy Efficiency According to Different Climatic Regions. Energy and Buildings, 73, 192-199. doi:10.1016/j.enbuild.2013.12.042 